NOTAS

\title{
LAS HUMANIDADES EN EL CONOCIMIENTO
}

\author{
Gerarld Nyenhuis*
}

$\mathbf{L}$ librerías, los libros de poesía que las acompañan, junto con obras de teatro, son manifestaciones de nuestra cultura. Pero son muy pocas las personas que los toman en serio como una fuente importante para adquirir un conocimiento del mundo en que vivimos. Se les toman como un tipo de diversión, un pasatiempo o un entretenimiento, pero no para aprender algo verdadero de la naturaleza de la realidad que habitamos.

Se trata de ficción, emoción, sentimiento e imaginación, y todo esto, nos dicen, tiende más a confundir que a informar. La información en estas obras es inventada, creada y fabricada, y, por eso, afirman, no es confiable. Lo imaginado, por definición, no habla de la verdad. La ficción, hemos oído, es producto de una mente sin estribos, una fantasía que sirve más para escapar de la realidad, y no para adentrarse en ella. Si buscamos información confiable de nuestra realidad, nos avi-

* Universidad Iberoamericana. san, tenemos que recurrir a las ciencias empíricas, y no a la literatura.

Esta actitud hacia la literatura es, desde luego, un producto de la revolución científica, iniciada en el siglo XVII y desarrollada er el fervor de la Ilustración del siglo XVIII. Fue refinada y llevada a nuevas alturas en el positivismo de los siglos XIX y XX. Este proceso es culpable de elevar la ciencia como una verdadera autoridad intelectual y relegar la literatura (y las otras humanidades) al estatus de mero entretenimiento. Es cierto que hubo protestas de tiempo en tiempo, pero, debido a que los mismos humanistas las hicieron, se las tomaron como una defensa de sus propios intereses. El efecto fue casi nulo, y la ciencia amplió su hegemonía.

La ciencia sigue dominante y todavía pone el marco, da la pauta, y establece las normas para lo que se pueda considerar como conocimiento. Sirve para enjuiciar a los otros que afirman tenerlo. Toda pretensión al verdadero saber tiene que sujetarse a los criterios del conocimiento científico. 


\section{NOTAS}

Todo enfoque que no se somete queda eliminado en el acto. El poder saber es disponible solamente a los que dominan el método científico. Todo lo demás es conjetura, opinión e imaginación, que no merece el nombre de conocimiento. El estudio de la literatura puede ser un buen pasatiempo, pero, según este enfoque, no resulta en conocimiento.

Este legado de la Ilustración, ejemplificado por la filosofía de David Hume, quien insistía en que los argumentos deductivos de la metafísi$\mathrm{ca}$, aunque lógicamente válidos, son empíricamente vacíos y no nos proporcionan información útil sobre la realidad, hace de la imaginación una fuente de error que, si confiamos en ella, nos conducirá a la abolición del verdadero conocimiento. Poemas, novelas, música, otras obras de arte y toda filosofía que no sea "positivista" no pueden considerarse como fuentes (ni potenciales) de conocimiento.

\section{Aprender de la ficción}

Los humanistas tomamos como nuestra tarea la de echar en reversa esta tendencia. No podemos tomar todo el campo de las humanidades como el área de nuestro trabajo, pero sí podemos tomar una parte como una ilustración. La parte de los estudios humanísiticos que tomaremos para exponer en esta ponencia es el área de la ficción, para saber si podemos alcanzar conocimiento por medio de ella.

Las novelas son las más conocidas obras de ficción, y, aunque comúnmente se acepta el hecho de que no es necesario que todo lo que está en una novela sea de ficción -puede haber algunas aseveraciones sobre el mundo real-se las toman como producto de la imaginación. Las novelas expresan fabricaciones, inventos y fantasías, que si se forman en una totalidad coherente, se hacen en un "mundo" de ficción que enchentra su realidad derivada del mundo "real". Sus semejanzas con el mundo llamado "real" son una parte esencial del mundo creado por el novelista, y el lector puede ser profundamente conmovido por lo imaginado, aún sabiendo que es imaginado.

Nos interesa saber que los que son conmovidos de esta manera por la novela, responden a sus sugerencias diciendo que han aprendido algo de ella, y lo que aprendieron tiene que ver con la realidad. Dicen: "De veras, así es la vida." Para ellos, la obra de ficción no sólamente nos proporciona información sobre el mundo real; también nos orienta para entenderlo y contextualizar lo que en él nos pudiera ser demasiado confuso. Imparte intuiciones, enfoques, valores y ópticas que nos permiten ver al mundo a una luz diferente, de un ángulo nuevo, y así comprenderlo más completa y correctamente.

El hecho de que aprendemos algo de la novela les parece obvio. Pero la 


\section{NOTAS}

pregunta de cómo aprendemos nos presenta un problema. El problema es cómo podemos saber lo que es la verdad si las declaraciones ficticias no son verdaderas descripciones de la realidad, sino que inventan su propia realidad. ¿Cómo podemos aprender la verdad acerca de nuestro mundo por este tipo de enunciados?

Hay una amplia suerte de literatura sobre el problema, y no podemos hacer resumen de toda ella aquí. Un punto importante que observamos de un repaso de los distintos enfoques sobre el problema es que tenemos que concluir que no hay solamente una manera de aprender. No siempre aprendemos de la misma manera. No aprendemos, por ejemplo, a jugar el tenis de la misma manera que aprendemos la historia, la geometría, tocar flauta o hacer galletas. Aprendemos la administración de una manera diferente de aprender una lengua, y aprendemos la segunda lengua y la tercera de una manera diferente de la primera. Aprendemos a cantar por otros caminos que aprendemos la moral, y no aprendemos a amar como aprendemos la química.

¿Qué aprendemos de la ficción? Parece obvio que adquirimos, de las novelas y cuentos que leemos, creencias fácticas (o factuales) acerca del mundo en que vivimos. Estas creencias, o sea creencias proposicionales acerca de nuestra realidad, por estar en forma proposicional, pueden ser correctas o incorrectas en sus afirma- ciones acerca de nuestra realidad. Las correctas, nadie las puede negar, nos dan un conocimiento verdadero de nuestra realidad. Las incorrectas contienen información incorrecta, como cualquier afirmación incorrecta, y por eso son equivocaciones, pero no son diferentes de las afirmaciones "científicas" equivocadas. La ficción, entonces, nos proporciona proposiciones $y$ creencias que fácticamente pueden ser verdaderas o falsas. Leer una obra de ficción es una fuente para adquirir estas proposiciones. Estas proposiciones nos pueden dar creencias verdaderas acerca del mundo en que vivimos.

Si la creencia que adquirimos de esta manera es verdadera, si la podemos "justificar", podemos decir que sabemos este dato, y tenemos conocimiento. (Se debe decir más sobre el proceso de "justificación", pero esto será tema de otro trabajo.) Desde luego, como se puede sospechar de lo dicho antes, estas creencias fácticas y verdades proposicionales no son el componente mayor de lo que aprendemos de la ficción. Sabemos esto del control de la prensa y las restricciones de las publicaciones que existen en todo el mundo. Hay cosas que nosotros mismos no queremos que se publiquen -la pornografía, por ejemplo. Esto muestra que estamos convencidos de que se pueden adquirir ciertas actitudes, valores y perspectivas -sean buenas o malas- de las obras de ficción. Tenemos que tomar decisiones 


\section{NOTAS}

en cuanto a estos valores y actitudes. Ellos mismos nos ponen en tela de juicio. Afectan nuestra vida y nuestra orientación hacia ella, y, de una manera especial, nuestras relaciones sociales, sobre todo en la familia y con el gobierno. La totalidad de nuestra vida está íntegramente relacionada con estas actitudes.

Además, y hay que hacer énfasis sobre esto, la gran parte de lo que aprendemos de las obras de ficción es de una naturaleza práctica. No lo contrasto con una naturaleza "teórica", debido a que lo más práctico es la buena teoría. Más bien, quiero indicar que lo que se aprende de la ficción es inmediatamente aplicable y que se trata de aquirir habilidades y pericia. La más notable, desde luego, y nada despreciable, es la habilidad de emplear la lengua. La lengua es la tela de la sociedad y la pericia en su uso tendrá buenos efectos en la vida comunitaria.

Pero no me refiero a esto. Más bien me refiero a dos tipos de habilidades. El primer tipo es la habilidad de estrategia. El héroe de una novela nos puede proporcionar estrategias prácticas para manejar situaciones difíciles: estrategias que podemos usar o adaptar para situaciones similares en que nos encontremos. Intelectualmente la novela nos puede enseñar estas estrategias, capacitándonos a tomar en cuenta aspectos del problema que no conocíamos, y así poder pensar más constructivamente sobre él. La experiencia nos permitirá pensar más efi- cientemente sobre los problemas de la vida, ya que los podemos reconocer por la experiencia vicaria que nos dio la obra de ficción. Así, las obras de ficción extienden o estiran nuestra experiencia y nuestro pensamiento.

Un segundo tipo de habilidad práctica no sólo amplía nuestro pensamiento, sino que radicalmente lo altera. La lectura de la ficción desarrolla habilidades que se pueden llamar conceptualizantes o cognoscitivas. Éstas son las habilidades que ofrecen nuevos caminos para pensar en nuestra realidad y nuevos esquemas para percibirla. El estudio de novelas, obras de teatro, cuentos y poemas puede capacitarnos en el empleo de nuevas estructuras conceptuales para enfocar situaciones tremendamente confusas. Nos permite ver objetos antiguos, demasiado familiares desde una nueva luz. Revela ángulos nuevos para percibir situaciones excesivamente conocidas, pero mal entendidas. De esta manera, la obra de ficción nos ayuda a percibir nuevos aspectos de objetos y situaciones, a observar inadvertidas relaciones entre ellos y entre otros acontecimientos, que, antes nos pasaron ignorados.

También la lectura de obras de ficción nos habilita para saber cómo se siente estar en ciertas situaciones, complejas y exigentes, sin que la salida sea fácil. La empatía que se aprende de una obra de ficción es una calidad esencial de la vida social. El poder sentirse en la situación de otros es una 
experiencia indispensable para la vida en comunidad. Mediante esta empatía aprendemos la experiencia universal y nos sentimos ligados con todo ser humano. Por ella entendemos al otro, y tenemos la seguridad que él nos pueda entender también, o por lo menos, podemos hacernos entender. La ficción nos da una nueva y eficaz inserción en la raza humana.

Esta conciencia, esta empatía, este darse cuenta, es notablemente no proposicional. Es un sentido que no puede ser captado en fórmulas matemáticas o por descripciones científicas. Se comunica solamente por obras de arte, por novelas y cuentos, por poemas y música. Apela a la imaginación y requiere que la imaginación sea desarrollada y disciplinada. Ninguna medida exacta, ninguna ecuación algebraica, ninguna descripción científica puede hacerme sentir cómo se siente un huérfano, o cómo sufre la viuda joven, cuyo marido fue asesinado; pero un poema o una novela sí puede hacerlo.

Todo esto es conocimiento práctico; tiene que ver con la vida, con el ser humano, con la sociedad. Es conocimiento esencial y debe ser obligatorio para cada universitario ( $\mathrm{y}$ todo hombre). 